\title{
Alon De Groot, Hannah Bernick-Greenberg, Excavations at the City of David 1978-1985 directed by Yigal Shiloh, vol. VIIA: Area E: Stratigraphy and Architecture
}

\section{Astrid Nunn}

\section{OpenEdition}

\section{Journals}

Édition électronique

URL : http://journals.openedition.org/abstractairanica/41624

DOI : $10.4000 /$ abstractairanica. 41624

ISSN : 1961-960X

Éditeur :

CNRS (UMR 7528 Mondes iraniens et indiens), Éditions de l'IFRI

Référence électronique

Astrid Nunn, «Alon De Groot, Hannah Bernick-Greenberg, Excavations at the City of David 1978-1985 directed by Yigal Shiloh, vol. VIIA: Area E: Stratigraphy and Architecture », Abstracta Iranica [En ligne], Volume 34-35-36 | 2017, document 57, mis en ligne le 15 juillet 2016, consulté le 02 octobre 2020 URL : http://journals.openedition.org/abstractairanica/41624 ; DOI : https://doi.org/10.4000/ abstractairanica. 41624

Ce document a été généré automatiquement le 2 octobre 2020.

Tous droits réservés 


\section{Alon De Groot, Hannah Bernick- Greenberg, Excavations at the City of David 1978-1985 directed by Yigal Shiloh, vol. VIIA: Area E: Stratigraphy and Architecture}

Astrid Nunn 


\section{RÉFÉRENCE}

Alon De Groot, Hannah Bernick-Greenberg. Excavations at the City of David 1978-1985 directed by Yigal Shiloh, vol. VIIA: Area E: Stratigraphy and Architecture. Jerusalem, Institute of Archaeology, the Hebrew University of Jerusalem, 2012 (Qedem, 53)

1 Les publications sur Jérusalem traitent peu souvent de l'époque achéménide. Tel est le cas des deux volumes complémentaires présentés ici. L'Area E est une grande surface située au centre de la ville de David. Des 16 strates la state 9 a été datée de l'époque achéménide grâce à la céramique retrouvée partout. Une installation domestique n'a au contraire été reconnue que dans l'Area E West (vol. VIIA, 173-176). La céramique est présentée par S. Zuckerman dans le vol VIIB (p. 31-56). Les types de bols carénés, de vases, cratères, bouteilles, flacons, cruches, amphores et lampes correspondent tous aux types classifiés à l'époque achéménide. Il s'agit de vaisselle quotidienne. Toute vaisselle peinte ou importée manque.

\section{Ce compte rendu concerne également une autre référence $\left(n^{\circ} 58\right)$ :}

3 Sharon Zuckerman. "The Pottery of Stratum 9 (the Persian Period) ", in : Alon de Groot, Hannah Bernick-Greenberg, Excavations at the City of David 1978-1985 directed by Yigal Shiloh, vol. VIIB: Area E: The Finds. 2012. (Qedem, 54)

\section{AUTEURS}

\section{ASTRID NUNN}

Université de Munich 